\title{
Big Data analysis: Intelligent Transportation Development Engine
}

\section{Qin Xiao*}

Department of Information Engineering, Lanzhou City University, Lanzhuo, Gansu 730070, China

\begin{abstract}
With the development of the times, people have unwittingly entered the information age. The information age has become a large amount of data bursting characteristics of the new era. In this feature people still seek to improve the production and quality of life. For the development of intelligent transportation needs of people's lives and make the real world, but in the construction of intelligent transportation among a large number of information data also adds to its change and difficulty, how to build an intelligent era of big data, security, low-cost, efficient and convenient of intelligent transportation systems become today people study. From the era of big data to intelligent traffic changes brought advantages and disadvantages, the era of big data to bring intelligent traffic problems and challenges, as well as the integration platform for massive data intelligent transportation intelligent transportation demand and large data structures has done a simple elaborate, it can provide some suggestions for areas of research that scientists.
\end{abstract}

\section{KEYWORDS}

Intelligent transportation

Big data

Application platform

\section{Introduction}

In recent years, countries are concerned about the "big data", sought by expanding its range of applications in the country, further release the potential value inherent in the data. March 29, 2012, the Obama administration announced the "big data research and development program", aimed at improving the capacity of existing people to acquire knowledge from large and complex data, and to accelerate the pace of the United States in science and engineering fields invention, enhance national security, change existing teaching and learning methods. Also in our July 22, 2012, held the "First China Big Data Applications Forum" in Beijing University, Major topics include the development trend of big data, big data applications in different scenarios, cloud computing and big data, big data and business intelligence It aimed to discuss the value

\section{Copyright $(92014$ Qin Xiao}

doi: $10.18686 /$ utc.vli1.3

Received: February 15, 2014; Accepted: April 25, 2014; Published online: June 28, 2014

This is an open-access article distributed under the terms of the Creative Commons Attribution Unported License (http://creativecommons.org/ licenses/by-nc/4.0/), which permits unrestricted use, distribution, and reproduction in any medium, provided the original work is properly cited.

${ }^{*}$ Corresponding author: Department of Information Engineering, Lanzhou City University, Lanzhuo, Gansu 730070, China. E-mail: xiaoqin_ 1z1@126.com of big data. At the First China International Exhibition of cloud computing technology and applications, held in April 2013, Secretary, Ministry of software services workers Chen said, "big data, I think it has four dimensions: volume, variety, development speed Finally, is the value of the complex, it can be said everywhere is gold, full of sand" [1].

With the rapid development of the city, traffic congestion, traffic pollution increasingly serious traffic accidents occur frequently. These are the problems to be solved in major cities. Intelligent transportation becomes the key to improve urban transportation. To this end, timely and accurate data and build traffic to obtain traffic data processing model is a prerequisite for building intelligent transportation, but this problem can be solved through big data technologies [2].

\section{The concept of Big Data}

Big Data "big data" is the second cloud computing, networking IT industry after another disruptive technological change, on the governance model, corporate decisionmaking, organizational and business processes, personal lifestyle will have a huge impact. In information technology, big data is a collection of data sets. This collection is so large and complex that it is difficult to be handled by existing database management tools [3].

From a wide variety of types of data, the ability to quick- 
ly obtain valuable information, it is the big data technologies. Big Data features are four levels: first, the data volume is huge. From TB level, jumped to PB level; second, the data type range. Including video, image, location information, sensor data, etc. Third, the value of low density and high value. In the video, for example, uninterrupted monitoring process, it may be useful data has only twelve seconds. Fourth, the processing speed is 1 second laws. This last point is and traditional data mining techniques are essentially different. In the transport sector, vast amounts of data including four types of data: sensor data (position, temperature, pressure, image, speed, RFID etc.); system data (logs, equipment records, MIBs, etc.); service data (charging information, Internet services and other information); application data (generated manufacturers, energy, transportation, performance, compatibility and other information). Many types have traffic data, but also the huge volume [4].

\section{Big Data technologies and Intelligent Transportation 3.1. Big Data: change the path of the traditional traf- fic management}

A substantial increase in the rapid development of social economy prompted the city the number of motor vehicles. Accelerated urbanization break the equilibrium state of urban road system, the traditional transport system cannot meet the needs of today's complex transport; traffic congestion has become thorny problem. With Big Data technologies can promote change traffic management modes. The main features of its big data technology change the traditional traffic in the following areas:

(1) Large virtual data can be solved across the limits of administrative areas. Division of administrative regions in order to effectively rule the country and management, and a country divided into different administrative areas. The division of administrative regions in promoting the autonomy of the individual, but also led to various local governments seeking to maximize their own interests' jurisdictions, while transportation infrastructure, transit traffic lines and other border areas between local government indifference. Virtual sex big data traffic, enabling its information management across the region, as long as the tenants in accordance with the principle of sharing relevant information, be able to solve cross-border management issues in the existing administrative region [2].

(2) The large data having information integration advantages and portfolio efficiency. All kinds of transportation management body of most cities scattered in different administrations, showing a fragmented phenomenon. Involving transportation of "relevant" more than 10 , each department has its own information systems, but these data only exists in the vertical business applications and a single and adjacent service system lacks common linkage. This decentralized management of the fragmentation caused by traffic, such as traffic information is scattered, the information content of a single other issues. Big data will help establish a comprehensive perspective of the traffic information system, to be integrated by different areas, different regions, different areas of "data warehouse", construction of public transportation information integration use patterns, to play overall traffic function, so as to find new value, bringing new opportunities. Such as weather, traffic, insurance sector data together, the transport sector can be studied efficiently disaster prevention and mitigation; IC card data binding sample survey, more efficient, more accurate measured traffic flow distribution [5].

(3) The intelligent performance of large data is preferably configured transport resources [4]. Traditional traffic management mainly relies on artificial means to plan and manage, difficult to achieve dynamic traffic management. Through the analysis of big data processing, it can assist traffic management to develop a better co-ordination and coordinated solutions. On the one hand reduce the human and material resources of the various transport sector operators; on the other hand it may be some truth to enhance the rational use of transportation resources. Such as multimode ground transportation network to determine the efficient allocation and traffic organization plan, multi-level ground transportation backbone network Green Wave traffic control and adaptive traffic signal control based on the results of big data.

(4) Fast and predictable performance of large data to enhance the level of traffic forecasts. Traditional thinking to improve traffic congestion in general is to increase infrastructure investment, namely widening roads, increase road mileage to improve traffic capacity, but this practice has not only limited land resources, and planning programs would to meet the vision needs are also open to question. After the data of various departments to accurately refine and build the appropriate traffic forecasting model that can effectively simulate future operational status, verify the feasibility of transportation technology solutions. In the field of real-time traffic prediction, rapid information processing capacity data for vehicle collision, lane change, real-time predictive driver behavior stately inspection, also have very high reliability.

\subsection{Big Data advantage in intelligent transportation applications}

\subsubsection{Improve traffic efficiency}

Big Data technology can improve the capacity of transport operators promote efficiency, road network, amenities efficiency and regulation of traffic demand analysis. Improving transport large quantities involved, and a large volume of data characteristic big help resolve this dilemma. For example, according to the American Institute of Los Angeles, through the organization of public transport vehicles and line optimization arrangements in vehicle operating efficiency increases, reduce 46 percent of vehicle transportation can provide the same or better transport services. City 
of London to take advantage of big data to reduce traffic congestion time and improve operating efficiency. When the vehicle is about to enter the congestion area, the sensor can tell the driver the best solution, which greatly reduces the economic cost of driving. Real-time big data, so that in the static idle data is processed and the need to use, you can be intelligent use to make traffic run more reasonable. Big Data technology has a high predictive ability, the probability of false positives and false negatives can be reduced at any time for dynamic real-time monitoring of traffic given. Therefore, when the driver was unable to predict the likelihood of traffic congestion, big data can help you understand in advance. For example, before the driver's view, big data management system will lead to the front of the route based on traffic congestion, weather factors, determine alternate routes to avoid congestion and to inform motorists via smartphone $[2,6]$.

\subsubsection{Improve traffic safety level}

Wide application of active safety and emergency rescue system effectively improve the traffic safety situation, while real-time and predictive Big Data technology can help increase data processing capacity of traffic safety systems. In the driver's automatic detection, video detection of driver fatigue, alcohol detector and other vehicle-mounted device drivers to real-time detection is in alertness, behavior, physical and mental state is normal. Meanwhile, the joint probe roadside inspection of vehicles running track, Big Data technology quickly integrate various sensor data, a comprehensive analysis of the security model to build after the vehicle security, which can effectively reduce the possibility of accidents. In terms of emergency relief, big data with its fast response time and comprehensive decisionmaking model that provides for the emergency command decision-making aid, improve emergency rescue, reduce casualties and property losses [7].

\subsubsection{Provide environmental monitoring methods}

Big Data technologies have an important role in mitigating the road traffic congestion; reduce the impact of car transport on the environment and other aspects. Through the establishment of monitoring and forecasting model for regional traffic emissions, operational and environmental data sharing traffic, build traffic operation and environmental data sharing test systems, big data technology can effectively analyze the impact of transport on the environment. Meanwhile, the analysis of historical data, big data technology can provide basis for decision making to reduce traffic delays and reduce emissions of intelligent traffic signal control, build prototype low-emission traffic signal control system and the environmental impact of vehicle emissions simulation system [8].

\section{Conclusion}

In the current era of big data, data filled far beyond the impact of the corporate sector, which not only bring business value, can also generate social value. With the development of information and communication technology, transportation data from the plight of poor steering datarich environment, and face many of the traffic data, how to extract valid data become the key according to user needs. However, the big data technology in the field of intelligent transportation applications also facing enormous challenges, including in the field of privacy, data processing hardware, data incompleteness, effectiveness of the model, these are our future continued need to explore and solve problems.

\section{References}

1. Han, Y. Q. (2013). Big Data: smart city development engine. [Online]. Retrieved from http://www.nti56.com/ news/detail/105004003/1574183268.html.

2. Yang, W. S. (2013). Intelligent traffic management a subversion of the traditional technological change. [Online]. Retrieved from Http://www.21its.com/Common/NewsDetail.aspx?ID=2013040811375806088.

3. Wang, T. (2012). Intel open platform for building big data ecosystem. [Online]. Retrieved from Http://server.zdnet.com.cn/server/2012/1211/2135509.shtml.

4. Mohan, S. (2012). Big Data Challenges and Opportunities. [Online]. Retrieved from Http://www.transportation. northwestern.edu /docs/2012.10.31.Sawhney.Big.Data. pdf.

5. Li, L. J. (2011). Data management and intelligent processing. ZTE Communications, 17(1), 38-41.

6. Rima, M. (2012). Travel and Transportation in the Age of Big Data. [Online]. Retrieved from http://www.ibmbigdatahub.com/blog/ travel-and-transportation-age-bigdata.

7. Greg, R. (2012). How big data drives intelligent transportation. [Online]. Retrieved from http://www.greenbiz. com/blog/2012/08/15/how-big-data-drives-intelligenttransportation? page $=0 \% 2 \mathrm{C}$.

8. U.S. Department of Transportation. (2012). Big Data Analytics: Driving Value Beyond the Hype. [Online].Retrieved from http://www.volpe.dot.gov/coi/outreach/colloquia/ tsda/docs/bigdatabro_508.pdf. 